\title{
Cerebrospinal Fluid Biomarkers and Proximity to Diagnosis in Preclinical Familial Alzheimer's Disease
}

\author{
John M. Ringman ${ }^{a}$ Giovanni Coppolab David Elashoff ${ }^{a}$ \\ Yaneth Rodriguez-Agudelo ${ }^{b}$ Luis D. Medina ${ }^{a}$ Karen Gylys ${ }^{a}$ \\ Jeffrey L. Cummings ${ }^{a}$ Greg M. Cole ${ }^{a}$ \\ ${ }^{a}$ Mary S. Easton Center for Alzheimer's Disease Research at UCLA, Los Angeles, Calif., USA; ${ }^{\text {b }}$ Laboratory of \\ Experimental Psychology, National Institute of Neurology and Neurosurgery, Mexico City, Mexico
}

\section{Key Words}

Cerebrospinal fluid • Biomarkers • Familial Alzheimer's disease, presymptomatic $\cdot$ PSEN1 gene $\cdot$ APP gene $\cdot$ tau protein $\cdot \beta$-Amyloid, 42-amino-acid form

\begin{abstract}
Background/Aims: Biological markers of utility in tracking Alzheimer's disease (AD) during the presymptomatic prodromal phase are important for prevention studies. Changes in cerebrospinal fluid (CSF) levels of 42 -amino-acid $\beta$-amyloid $\left(A \beta_{42}\right)$, total tau protein (t-tau) and phosphorylated tau at residue 181 ( $p$-tau tr1 $_{1}$ ) during this state are incompletely characterized. Methods: We measured CSF markers in 13 carriers of familial AD (FAD) mutations that are fully penetrant for causing AD (PSEN1 and APP) and in 5 non-mutationcarrying family members. Results: Even among the entirely presymptomatic mutation carriers $(n=9), A \beta_{42}$ was diminished (388.7 vs. $618.4 \mathrm{pg} / \mathrm{ml}, \mathrm{p}=0.004)$, and t-tau (138.5 vs. $50.5 \mathrm{pg} / \mathrm{ml}, \mathrm{p}=0.002$ ) and $\mathrm{p}-\operatorname{tau}_{181}$ (71.7 vs. $24.6 \mathrm{pg} / \mathrm{ml}, \mathrm{p}=$ $0.003)$ were elevated. There was a negative correlation between $A \beta_{42}$ levels and age relative to the family-specific age of dementia diagnosis. Conclusions: Our data are consistent with a decline in CSF $A \beta_{42}$ levels occurring at least 20 years prior to clinical dementia in FAD.
\end{abstract}

Copyright $\odot 2012$ S. Karger AG, Basel

\section{KARGER}

Fax +41613061234 E-Mail karger@karger.ch www.karger.com
(C) 2012 S. Karger AG, Basel

$1420-8008 / 12 / 0331-0001 \$ 38.00 / 0$

Accessible online at:

www.karger.com/dem

\section{Introduction}

It is estimated that the prevalence of Alzheimer's disease (AD) will be 11-16 million by 2050 [1]. A better understanding of the biochemical changes occurring during the earliest stages of $\mathrm{AD}$ will help us better understand, diagnose, and hopefully develop treatments to prevent it. Decreased cerebrospinal fluid (CSF) levels of the 42-amino acid length derivate of amyloid precursor protein $\left(A \beta_{42}\right)$ are well characterized in established $A D$ [2]. This is commonly believed to represent a shift in equilibrium from a soluble form in the CSF to its deposition in the central nervous system. Elevated CSF levels of microtubule-associated protein tau (tau) are also found in $\mathrm{AD}[3]$ though they are not specific for this disorder [4, 5], suggesting it is a general marker for cerebral damage. Consistent with the hyperphosphorylation of tau observed in the brains of persons with AD, elevated CSF phosphorylated tau (p-tau) is observed in AD and appears to be more specific [5]. This has led to the use of these markers as a commercially available diagnostic test. Decreased CSF $A \beta_{42}$ and increased total tau (t-tau) and tau phosphorylated at residue $181\left(\mathrm{p}\right.$ - $\left.\operatorname{tau}_{181}\right)$ have also been demonstrated to be predictive of progression [6] and the future development of $\mathrm{AD}$ in persons with mild cog-

Assoc. Prof. John M. Ringman, MD, MS

Mary S. Easton Center for Alzheimer's Disease Research

Department of Neurology, David Geffen School of Medicine at UCLA

10911 Weyburn Avenue 200, Los Angeles, CA 90095-7226 (USA)

Tel. +1 310794 3231, E-Mail jringman@mednet.ucla.edu 
nitive impairment [7], providing supporting evidence that the AD pathological process precedes overt dementia by years. At what point during the presymptomatic phase these CSF changes begin to appear is currently incompletely characterized, in part because it is challenging to obtain such samples on normal, middle-aged persons certain to develop $\mathrm{AD}$ at a later point.

Unlike late-onset AD in which our ability to predict the illness is imperfect, persons inheriting autosomal dominant mutations causing fully penetrant $\mathrm{AD}$ due to mutations in the PSEN1 and APP genes (familial AD or FAD), in whom the illness is essentially fully penetrant, provide the opportunity to study persons in the presymptomatic stage [8]. Moonis et al. [9] described decreased $\mathrm{A} \beta_{42}$ and a trend towards increased t-tau and $\mathrm{p}-\mathrm{tau}_{181}$ in the CSF of 6 presymptomatic FAD mutation carriers. We previously showed that a cohort of 7 FAD mutation carriers (5 presymptomatic) who were an average of 11 years younger than the typical age of $\mathrm{AD}$ diagnosis in their family had elevated CSF t-tau and $\mathrm{p}$ - $\operatorname{tau}_{181}$, and decreased CSF $A \beta_{42} / A \beta_{40}$ ratios compared to non-mutation-carrying family members [10]. Fortea et al. [11] found $A \beta_{42}$ levels to be diminished prior to elevation in tau levels in presymptomatic FAD mutation carriers. In 1 subject studied prospectively by our group who was 22 years prior to the characteristic age of disease diagnosis in his/her family at the initial lumbar puncture and underwent repeat lumbar puncture 4.5 years later, $A \beta_{42}$ levels had diminished and t-tau and $\mathrm{p}-\mathrm{tau}_{181}$ had increased markedly in the interim [12].

In the current study we evaluated the levels of CSF $\mathrm{A} \beta_{42}, \mathrm{t}$-tau, and $\mathrm{p}$-tau ${ }_{181}$ in a larger cohort that better enables us to define the levels of such biomarkers in relation to subjects' proximity to the typical age of disease diagnosis in their family.

\section{Methods}

\section{Subjects and Clinical Data}

Eighteen subjects with or at risk for FAD due to PSEN1 (A431E, L235V, S212Y) or APP (V717I) mutations participated in a comprehensive study assessing clinical, cognitive, imaging, and biochemical changes occurring during the presymptomatic period of FAD. Age of disease onset tends to be consistent within families but varies between them [13], particularly with regard to the A431E PSEN1 [14] and V717I APP [15] mutations represented in this cohort. Therefore, a family-specific 'adjusted age' based on the median age of disease diagnosis in each subject's family was calculated to normalize subjects with regard to their proximity to the time of clinical disease. Evaluations included the Mini Mental State Examination [16] and the Clinical Dementia Rating (CDR) scale [17] performed by an investigator blind to the subjects' mu- tation status except for 2 subjects who had undergone revealing clinical genetic testing. All subjects signed written informed consent and all procedures were approved by the UCLA Institutional Review Board.

\section{CSF Analyses}

CSF was collected at various times of the day within the same week as clinical assessments. CSF was aspirated and placed in polystyrene tubes on ice. Within $2 \mathrm{~h}$ CSF was centrifuged and aliquoted into $0.5-\mathrm{ml}$ siliconized polypropylene tubes and frozen at $-80^{\circ} \mathrm{C}$. CSF was analyzed for $\mathrm{A} \beta 42, \mathrm{t}$-tau, and $\mathrm{p}$-tau ${ }_{181}$ levels using Innogenetics INNO-BIA AlzBio3 multiplex assays on standardized xMAP Luminex technology.

\section{Genetic Analyses}

DNA was extracted and apolipoprotein E (APOE) genotyping performed using standard techniques. The presence of the A431E and L235V substitutions in PSEN1 were assessed using restriction fragment length polymorphism analyses. The patient carrying the S212Y PSEN1 mutation was ascertained using a commercial test where the open reading frame of the coding region of the PSEN1 gene was sequenced. The presence of the V717I substitution in APP was assessed with direct sequencing. CSF and genetic analyses were performed by personnel blind to all clinical information.

\section{Statistical Analyses}

Adjusted age, Mini Mental State Examination scores, and levels of $A \beta_{42}$, t-tau, and $\mathrm{p}$-tau $\mathrm{t}_{181}$ were compared between mutation carriers (MCs) and noncarriers (NCs) by Student's t tests using $\mathrm{p}$ values for unequal variances. $A P O E$ genotype frequency was compared between MCs and NCs using $\chi^{2}$ tests. The Pearson correlation coefficient was used to assess relationships between adjusted age and marker levels. All analyses were performed using PASW Statistics 18 .

\section{Results}

Thirteen subjects were MCs and 5 were NCs. Eleven MCs had PSEN1 mutations; 2 had APP mutations. Among the 13 MCs, 9 were asymptomatic (CDR scores of 0 ), 2 were very mildly symptomatic (CDR scores of 0.5$)$ and 1 was mildly $(\mathrm{CDR}=1)$ and 1 was moderately $(\mathrm{CDR}=2)$ demented. There were no significant differences between MCs and NCs in adjusted age, gender, or APOE genotype (table 1). Specific data regarding MCs and NCs with respect to gender, absolute age, age range, and mutation for which they were at risk are not shown to maintain confidentiality.

$A \beta_{42}$ levels were significantly lower and t-tau and $p$ $\operatorname{tau}_{181}$ levels significantly higher in FAD MCs relative to NCs (table 1). When only asymptomatic subjects were considered, the differences in $A \beta_{42}$, $t$-tau and $p$-tau 181 between MCs and NCs were diminished but remained significant. 


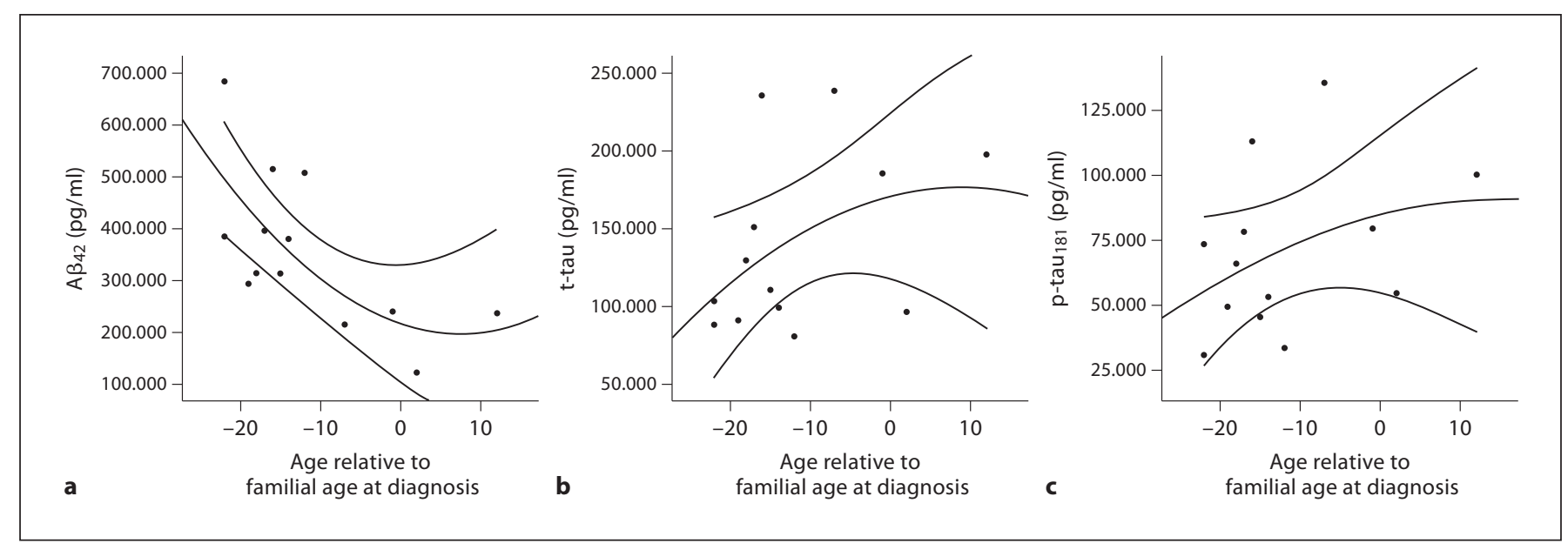

Fig. 1. Levels of CSF biomarkers with age adjusted for family-specific age at disease diagnosis. Lines represent quadratic fit lines with $95 \%$ confidence intervals. a $\mathrm{A} \beta_{42}$ levels drop between 20 and 10 years prior to the expected age of diagnosable dementia. b t-tau. c p-tau 181 .

Table 1. Descriptive results and results of Student's t tests comparing FAD MCs and NCs

\begin{tabular}{|c|c|c|c|c|c|}
\hline & $\begin{array}{l}\text { FAD NCs } \\
(\mathrm{n}=5)\end{array}$ & $\begin{array}{l}\text { All FAD MCs } \\
(\mathrm{n}=13)\end{array}$ & $\begin{array}{l}\mathrm{p} \text { values } \\
\text { NCs vs. } \\
\text { all FAD MCs }\end{array}$ & $\begin{array}{l}\text { Asymptomatic } \\
\text { FAD MCs } \\
(\mathrm{n}=9)\end{array}$ & $\begin{array}{l}\text { p values } \\
\text { NCs vs. } \\
\text { asymptomatic } \\
\text { FAD MCs }\end{array}$ \\
\hline Adjusted age & $-6 \pm 14.4$ & $-11.5 \pm 10.2$ & 0.47 & $-16.7 \pm 4.6$ & 0.18 \\
\hline MMSE scores & $28.8 \pm 1.1$ & $25.8 \pm 6.4$ & 0.12 & $28.6 \pm 0.9$ & 0.68 \\
\hline APOE genotypes No. $2 / 3,3 / 3,3 / 4$ & $0,3,2$ & $3,9,1$ & 0.17 & $3,5,1$ & 0.23 \\
\hline $\mathrm{A} \beta_{42}, \mathrm{pg} / \mathrm{ml}$ & $618.4 \pm 100.0$ & $354.3 \pm 149.3$ & 0.001 & $388.7 \pm 138.4$ & 0.004 \\
\hline $\mathrm{t}-\mathrm{tau}, \mathrm{pg} / \mathrm{ml}$ & $50.5 \pm 9.4$ & $139.0 \pm 56.8$ & $<0.001$ & $138.5 \pm 59.1$ & 0.002 \\
\hline $\mathrm{p}-\mathrm{tau}_{181}, \mathrm{pg} / \mathrm{ml}$ & $24.6 \pm 9.2$ & $70.3 \pm 31.1$ & $<0.001$ & $71.7 \pm 33.6$ & 0.003 \\
\hline
\end{tabular}

Adjusted age is age relative to the median age of dementia diagnosis in the probands' families.

$\mathrm{A} \beta_{42}$ levels negatively correlated with adjusted age in MCs $(r=-0.64, \mathrm{p}=0.018)$. Plotting $\mathrm{A} \beta_{42}$ levels against adjusted age (fig. 1a) suggests a substantial decrease occurring between 20 and 10 years prior to the approximate age at which a diagnosis of dementia is anticipated. An increase in t-tau (fig. 1b) and p-tau 181 (fig. 1c) levels with age in MCs is also suggested though the relation is less strong.

\section{Discussion}

In this study of 13 persons carrying FAD mutations, we found diminished CSF levels of $A \beta_{42}$, and increased levels of $\mathrm{t}$-tau and $\mathrm{p}$-tau $\mathrm{ta1}_{181}$ relative to non-mutation-car- rying family members. Consistent with the findings of Fortea et al. [11], these differences persisted when only presymptomatic MCs were analyzed, indicating they occur during the presymptomatic stage. Relating these levels with adjusted age indicates a decline in $\mathrm{A} \beta_{42}$ occurring between 20 and 10 years prior to the expected age of disease diagnosis. This is consistent with our serial observation of a subject that showed a decrease in CSF $A \beta_{42}$ between 22 years and 17 years prior to the age of diagnosis in their family [12]. There were trends for t-tau and $\mathrm{p}$ - $\operatorname{tau}_{181}$ to increase over time in this study and the longitudinal report [12] but the current data suggest more variability in these measures. In our prior structural imaging studies in this same population, we did not find substan- 
tial differences between MCs and NCs during the preand early symptomatic stage [18], indicating that CSF changes precede measurable cerebral atrophy.

Though change in these CSF biomarkers in relation to pathology is suspected, there is not yet substantial data regarding their utility in predicting the development of $\mathrm{AD}$ or of their longitudinal change in presymptomatic persons. A study of elderly nondemented persons found that though baseline CSF $A \beta_{42}$, $t$-tau, and $\mathrm{p}$-tau ${ }_{181}$ levels were not related to cognitive function, decreasing CSF $\mathrm{A} \beta_{42}$ and increasing $\mathrm{p}$-tau ${ }_{181}$ levels over 4 years' time were associated with cognitive decline [19]. Data from the Alzheimer's Disease Neuroimaging Initiative show that decreases in CSF $A \beta_{42}$ were greater in persons with normal cognition than in those with mild cognitive impairment or $A D$ [20], suggesting $A \beta_{42}$ changes can occur prior to symptoms. This study does not address CSF biomarker levels in the presymptomatic state in those certain to develop the disease.

A prior study of CSF biomarkers in persons carrying the APOE $\varepsilon 4$ allele also demonstrated decreases in $\mathrm{A} \beta_{42}$ without changes in tau during the presymptomatic period [21]. Unlike research into the genetic risk of AD conferred by the APOE $\varepsilon 4$ genotype, our study takes advantage of the predictability of age of disease onset in persons with FAD mutations to estimate the time course of presymptomatic CSF changes. Being a cross-sectional study, we cannot address the intraindividual longitudinal course. Nonetheless, our findings suggest declines in CSF $A \beta_{42}$ occur $20-10$ years prior to the expected age of dementia diagnosis though they do not exclude the possibility of earlier changes.

A weakness of our study is that it is not clear to what extent findings in FAD are generalizable to late-onset AD. Though there are many clinical and pathological similarities between FAD and late-onset AD, FAD can have atypical clinical (e.g. seizures [22], headaches [23]), imaging [24], and pathological [25] features. In addition, age influences CSF biomarker levels and therefore the young age and the relative lack of comorbidity in young FAD mutation carriers makes comparison to late-onset $\mathrm{AD}$ more challenging.

As the most commonly cited mechanism by which FAD mutations cause disease is through increasing absolute or relative production of $A \beta_{42}$ and increased plasma $A \beta_{42}$ in these individuals is well described $[10,26]$, one might expect CSF levels of $A \beta_{42}$ to be elevated prior to its deposition in the brain. Our data do not exclude this possibility; demonstration of this awaits larger FAD data sets such as those being produced by the Dominantly Inherited Alzheimer Network (http://www.dian-info.org/) and the Alzheimer's Prevention Initiative. Larger populations such as these are required to disentangle the influences of specific mutation, other genetic (e.g. APOE), epigenetic, and environmental influences on the disease process in individuals with FAD. Better understanding of the course of biomarker changes in presymptomatic FAD will help us design proof-of-concept studies for prevention of the illness [27].

\section{Acknowledgements}

This study was supported by PHS K08 AG-22228, California DHS No. 04-35522, Alzheimer's Disease Research Center Grant P50 AG-16570 from the National Institute on Aging, the Easton Consortium for Alzheimer's Disease Drug Discovery and Biomarkers, General Clinical Research Centers Program M01RR00865, the Sidell Kagan Foundation, and the Shirley and Jack Goldberg Trust.

\section{References}

1 Thies W, Bleiler L: Alzheimer's disease facts and figures. Alzheimers Dement 2011;7:208244.

-2 Motter R, Vigo-Pelfrey C, Kholodenko D, et al: Reduction of beta-amyloid peptide 42 in the cerebrospinal fluid of patients with Alzheimer's disease. Ann Neurol 1995;38:643648

-3 Andreasen N, Vanmechelen E, Van de Voorde A, et al: Cerebrospinal fluid tau protein as a biochemical marker for Alzheimer's disease: a community-based follow-up study. J Neurol Neurosurg Psychiatry 1998;64:298305 .
4 Zetterberg H, Hietala MA, Jonsson M, et al: Neurochemical aftermath of amateur boxing. Arch Neurol 2006;63:1277-1280.

$\checkmark 5$ Hesse C, Rosengren L, Andreasen N, et al: Transient increase in total tau but not phospho-tau in human cerebrospinal fluid after acute stroke. Neurosci Lett 2001;297:187190.

6 Okonkwo OC, Mielke MM, Griffith HR, et al: Cerebrospinal fluid profiles and prospective course and outcome in patients with amnestic mild cognitive impairment. Arch Neurol 2011;68:113-119.
Mattsson N, Zetterberg H, Hansson O, et al: CSF biomarkers and incipient Alzheimer disease in patients with mild cognitive impairment. JAMA 2009;302:385-393.

$\$ 8$ Ringman JM: What the study of persons at risk for familial Alzheimer's disease can tell us about the earliest stages of the disorder: a review. J Geriatr Psychiatry Neurol 2005;18: 228-233.

-9 Moonis M, Swearer JM, Dayaw MP, et al: Familial Alzheimer disease: decreases in CSF Abeta42 levels precede cognitive decline. Neurology 2005;65:323-325. 
10 Ringman JM, Younkin SG, Pratico D, et al: Biochemical markers in persons with preclinical familial Alzheimer disease. Neurology 2008;71:85-92.

11 Fortea J, Llado A, Bosch B, et al: Cerebrospinal fluid biomarkers in Alzheimer's disease families with PSEN1 mutations. Neurodegener Dis 2011;8:202-207.

12 Ringman JM, Taylor K, Teng E, Coppola G, Gylys K: Longitudinal change in CSF biomarkers in a presymptomatic carrier of an APP mutation. Neurology 2011;76:21242125.

-13 Fox NC, Kennedy AM, Harvey RJ, et al: Clinicopathological features of familial Alzheimer's disease associated with the M139V mutation in the presenilin 1 gene. Pedigree but not mutation specific age at onset provides evidence for a further genetic factor. Brain 1997;120:491-501.

14 Murrell J, Ghetti B, Cochran E, et al: The A431E mutation in PSEN1 causing familial Alzheimer's disease originating in Jalisco State, Mexico: an additional fifteen families. Neurogenetics 2006;7:277-279.

$\checkmark 15$ Mullan M, Tsuji S, Miki T, et al: Clinical comparison of Alzheimer's disease in pedigrees with the codon $717 \mathrm{Val} \rightarrow$ Ile mutation in the amyloid precursor protein gene. Neurobiol Aging 1993;14:407-419.
16 Folstein MF, Folstein SE, McHugh PR: 'Mini-mental state': a practical method for grading the cognitive state of patients for the clinician. J Psychiatr Res 1975;12:189-198.

17 Morris JC: Clinical dementia rating: a reliable and valid diagnostic and staging measure for dementia of the Alzheimer type. In Psychogeriatr 1997;9(suppl 1):173-176, discussion 177-178.

18 Apostolova LG, Hwang KS, Medina LD, et al: Cortical and hippocampal atrophy in patients with autosomal dominant familial Alzheimer's disease. Dement Geriatr Cogn Disord 2011;32:118-125.

19 Stomrud E, Hansson O, Zetterberg H, Blennow K, Minthon L, Londos E: Correlation of longitudinal cerebrospinal fluid biomarkers with cognitive decline in healthy older adults. Arch Neurol 2010;67:217-223.

20 Lo RY, Hubbard AE, Shaw LM, et al: Longitudinal Change of Biomarkers in Cognitive Decline. Arch Neurol 2011;68:1257-1266.

-21 Morris JC, Roe CM, Xiong C, et al: APOE predicts amyloid-beta but not tau Alzheimer pathology in cognitively normal aging. Ann Neurol 2010;67:122-131.
22 Takao M, Ghetti B, Murrell JR, et al: Ectopic white matter neurons, a developmental abnormality that may be caused by the PSEN1 S169L mutation in a case of familial AD with myoclonus and seizures. J Neuropathol Exp Neurol 2001;60:1137-1152.

23 Ringman JM, Romano JD, Medina LD, et al: Increased prevalence of significant recurrent headache in preclinical familial Alzheimer's disease mutation carriers. Dement Geriatr Cogn Disord 2008;25:380-384.

24 Klunk WE, Price JC, Mathis CA, et al: Amyloid deposition begins in the striatum of presenilin-1 mutation carriers from two unrelated pedigrees. J Neurosci 2007;27:61746184

25 O’Riordan S, McMonagle P, Janssen JC, et al: Presenilin-1 mutation (E280G), spastic paraparesis, and cranial MRI white-matter abnormalities. Neurology 2002;59:1108-1110.

26 Scheuner D, Eckman C, Jensen M, et al: Secreted amyloid beta-protein similar to that in the senile plaques of Alzheimer's disease is increased in vivo by the presenilin 1 and 2 and $A P P$ mutations linked to familial Alzheimer's disease. Nat Med 1996;2:864-870.

27 Bateman RJ, Aisen PS, De Strooper B, et al: Autosomal-dominant Alzheimer's disease: a review and proposal for the prevention of Alzheimer's disease. Alzheimers Res Ther 2011;2:35. 